\title{
Kinematic properties of upper limb trajectories in idiopathic torsion dystonia
}

\author{
Rivka Inzelberg, Tamar Flash, Edna Schechtman, Amos D Korczyn
}

\begin{abstract}
The kinematic properties of upper limb trajectories of simple reaching movements have been analysed in patients with idiopathic torsion dystonia (ITD). The velocity profiles differed from those of neurologically healthy subjects by being less symmetric. In several patients movement execution was slow due to a longer deceleration time. This phenomenon was even more conspicuous in the absence of visual feedback from the limb and was accompanied by a significant decrease in the final accuracy. These findings show that patients with ITD have deficits in central motor mechanisms beyond abnormal muscle activation patterns. Similarities between kinematic properties of patients with ITD and patients with Parkinson's disease including the deterioration of motor performance in ITD in the absence of visual feedback from the limb, suggest the existence of abnormalities in sensorimotor integration in both diseases.
\end{abstract}

$(\mathcal{F}$ Neurol Neurosurg Psychiatry 1995;58:312-319)

Keywords: kinematic properties; upper limb trajectories; idiopathic torsion dystonia

Idiopathic torsion dystonia (ITD) is characterised by abnormal movements and postures.

Department of Neurology, Tel-Aviv Medical Center, Tel-Aviv, Israel $\mathrm{R}$ Inzelberg A D Korczyn

Department of Applied Mathematics and Computer Science, The Weizmann Institute of Science, Rehovot, Israel $\mathbf{R}$ Inzelberg

T Flash

Computer Center, The Weizmann Institute of Science, Rehovot, Israel Correspondence to: Correspondence Department of Applied Mepartment of Applied Science, The Weizman Institute of Science, Rehovot 76100, Israel.

Received 15 March 1994 and in revised form 29 July 1994.

Accepted 26 August 1994 genetics of ITD, ${ }^{12}$ several domains in the pathophysiology of this disease remain subjects for research. ${ }^{3}$ The exact anatomical site affected in dystonia is unknown, although symptomatic dystonias ${ }^{4}$ point to the putamen, caudate, or thalamus as the major affected structures. Muscle activation patterns in ITD, investigated by the analysis of EMG signals, have shown that instead of normal alternating agonist-antagonist contractions, patients with ITD exhibit prolonged EMG bursts in the activated muscles, abnormal cocontraction of antagonistic muscles, and spread to unrelated muscles. ${ }^{5-8}$

The mechanisms postulated to underly such abnormal muscle activation include defective reciprocal inhibition, which might reflect abnormalities at spinal or supraspinal levels,-for example, of descending commands to spinal inhibitory interneurons. ${ }^{9-12}$ The functional state of hierarchically higher structures enrolled in the programming of movement and causing the abnormal muscle activities in ITD remains obscure. Moreover, a previous kinematic study analysing rapid elbow movements, has shown normal kinematic properties of this single joint movement in ITD. ${ }^{13}$

Whereas single joint movements are relatively simple, most daily activities employ simultaneous movements about several joints. An important review has stressed that the analysis of multijoint and complex movements might contribute to the understanding of the mechanisms underlying the pathophysiology of basal ganglia diseases. ${ }^{14}$ Thus we were interested in studying multijoint movements in ITD.

When multijoint movements of the upper limb are considered, a distinction between the hand path and hand trajectory should be made. ${ }^{15}$ "Path" is defined as the geometrical curve that the hand follows in space, and "trajectory" refers both to the path and to the time course of position along the path. ${ }^{15}$ In normal subjects, hand paths of planar horizontal reaching movements are roughly straight and the speed first increases and then decreases resulting in bell shaped velocity profiles. ${ }^{16}$ The durations of the two components are roughly equal, ${ }^{16}$ although under strict accuracy demands the decelerative part might be longer. ${ }^{17}$ This division into accelerative and decelerative phases relates to a proposal made a century ago by Woodworth, ${ }^{18}$ who stated that a movement is composed of an "initial impulse", believed to be preplanned, and a subsequent "current control", which is corrected by sensory feedback.

Recent data suggest the existence of an 
Table 1 Characteristics of patients

\begin{tabular}{|c|c|c|c|c|c|c|}
\hline Subject & Age & Sex & $\begin{array}{l}\text { Duration of } \\
\text { disease }(y)\end{array}$ & Treatment ${ }^{*}$ & $\begin{array}{l}\text { Involved } \\
\text { body parts }\end{array}$ & $\begin{array}{l}\text { Severity of } \\
\text { dystonia }\end{array}$ \\
\hline $\begin{array}{l}\text { S1 } \\
\text { S2 } \\
\text { S3 } \\
\text { S4 } \\
\text { S5 } \\
\text { S6 } \\
\text { S7 } \\
\text { S8 }\end{array}$ & $\begin{array}{l}19 \\
20 \\
37 \\
28 \\
24 \\
43 \\
34 \\
32\end{array}$ & $\begin{array}{l}\mathrm{F} \\
\mathrm{M} \\
\mathrm{F} \\
\mathrm{F} \\
\mathrm{F} \\
\mathrm{M} \\
\mathrm{M} \\
\mathrm{M}\end{array}$ & $\begin{array}{r}8 \\
2 \\
27 \\
18 \\
15 \\
15 \\
23 \\
13\end{array}$ & $\begin{array}{l}\text { Trihexyphenidyl } \\
\text { None } \\
\text { None } \\
\text { Trihexyphenidyl } \\
\text { Carbamazepine } \\
\text { Trihexyphenidyl } \\
\text { None } \\
\text { Trihexyphenidyl } \\
\text { Diazepam }\end{array}$ & $\begin{array}{l}\text { UL, trunk } \\
\text { UL, } \\
\text { UL, trunk, neck } \\
\text { UL, LL } \\
\text { Neck, UL } \\
\text { Neck, UL, trunk } \\
\text { UL, LL, neck } \\
\text { UL, spasmodic } \\
\text { dysphonia }\end{array}$ & $\begin{array}{l}\text { Moderate } \\
\text { Mild } \\
\text { Moderate } \\
\text { Moderate } \\
\text { Mild } \\
\text { Moderate } \\
\text { Mild } \\
\text { Mild }\end{array}$ \\
\hline
\end{tabular}

*Treatment was withdrawn at least 24 hours before the study. Median age for patients with ITM (n=8) was 28; Median age (range) for controls $(n=6)$ was $30(17-36) ; U L=$ Upper limbs; LL = Lower limbs.

identified in a countrywide study on the clinical course of the disease in Israel. ${ }^{21}$ They were all Ashkenazi who carry the 9q DYT gene mutation. ${ }^{22}$ Table 1 summarises their characteristics. The diagnosis was based on the presence of a progressive dystonic posture or movement, and exclusion criteria included perinatal jaundice or anoxia, metabolic disorders, brain trauma or infection, and exposure to drugs that could possibly induce dystonia, as well as the existence of sensory, cognitive, cerebellar, pydramidal, or peripheral nerve pathology. Patients had no medication for at least 24 hours before the experiment and gave informed consent for participation in the study.

\section{EXPERIMENTAL APPARATUS}

The experimental apparatus consisted of a 60 $\times 60 \mathrm{~cm}$ horizontal digitising table and a pen-like stylus (fig 1). This table, which was linked to a micro PDP computer allowed accurate localisation of the stylus position at a rate of $100 \mathrm{~Hz}$. During each trial, two light emitting diodes beneath the transparent surface of the table were used to mark origin and destination points for the hand movements.

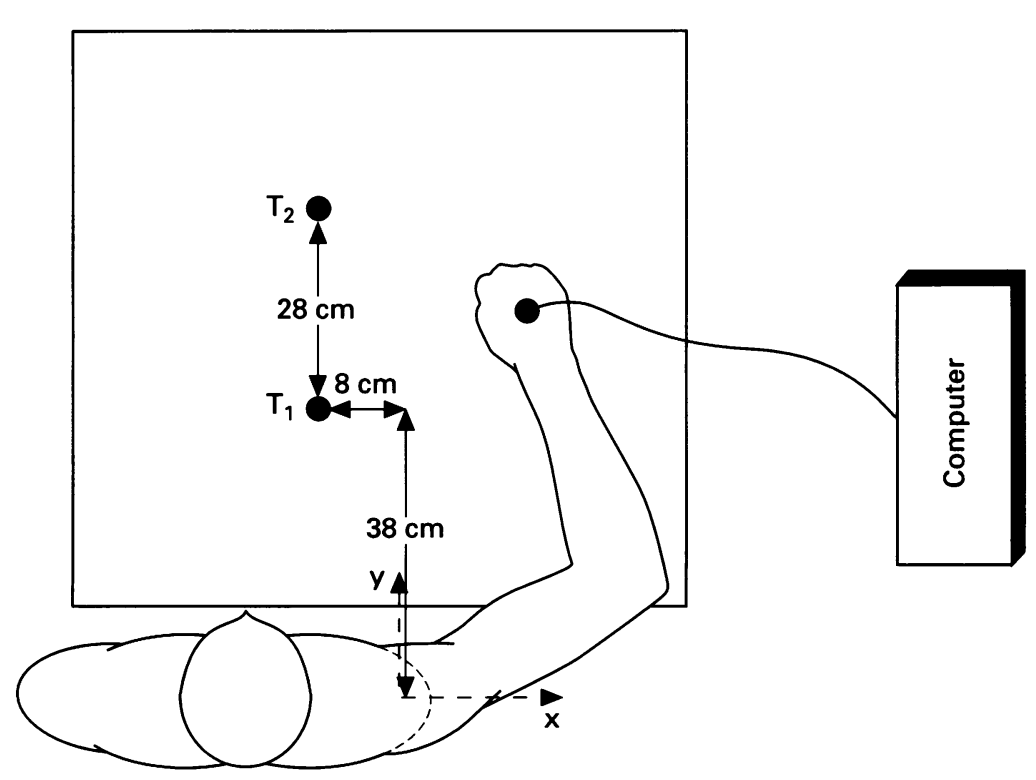

Figure 1 The apparatus. The initial and destination points are marked by the solid circles. Target location with respect to a Cartesian coordinate system located at the shoulder and the distance between the targets are shown. The origin and destination targets are marked by $T 1$ and $T 2$ respectively.
Targets were $1.0 \mathrm{~cm}$ in diameter and the subject was instructed to move the stylus from one target to the other. Figure 1 shows the target positions with respect to the subject's shoulder. The sequence of target illumination was controlled by a computer, which was also used for storing and further analysis of the movement records, including visualisation of the trajectories on a graphic display terminal.

\section{EXPERIMENTAL DESIGN}

Subjects were tested while seated, holding the stylus in their right hand (all were right handed). The shoulder was restrained and the wrist braced, so that the movements were confined to elbow and shoulder rotations in a horizontal plane at the level of the subject's shoulder. The experiment was performed while the room was illuminated, with the subjects able to see both the target and the moving limb (visual feedback condition). The same procedure was repeated in darkness. In this situation (no visual feedback condition) subjects wearing red tricolor gelatine filter glasses were unable to observe the moving limb, but could see the light emitting diodes, which remained on throughout the movement.

Subjects were told that the target light emitting diodes would be first illuminated (duration $800 \mathrm{~ms}$ ), then turned off (for 300 ms) and subsequently turned on again, and would then remain on throughout the movement. They were instructed to move immediately on the second target illumination and to perform a movement the duration of which was to be roughly equal to the duration of the first illumination-that is, $800 \mathrm{~ms}$. No specific instructions with regard to accuracy were given. Back and forth movements between the same pair of targets were repeated 10 times.

\section{DATA ANALYSIS}

With appropriate computer analysis programs, the following variables were derived from the recorded data:

\section{Spatial and kinematic properties}

(a) The trajectory path and the velocity profile; (b) final position error. The final position of each movement corresponded to the endpoint of the hand path. The spatial coordinates of the final position for all movements were combined to calculate the mean final position. The final error was represented by the magnitude (FEM) and the direction (FED) of a 
vector originating from the target to the mean final position. (c) The peak velocity (PV) was determined at the point in time at which the tangential acceleration became zero. (d) The initial peak acceleration (IPAV) was defined as the acceleration value of the first peak in the acceleration profile.

\section{Temporal properties}

The temporal properties were defined as (a) the reaction time (RT): the time elapsing between the second illumination of the destination target and movement initiation; (b) movement time (MT): the time interval elapsing between movement initiation and until tangential velocity first became zero; (c) MT was further divided into the acceleration time (AT): the time elapsing from movement initiation and until the acceleration first became zero and the subsequent deceleration time (DT) lasting until movement termination; (d) acceleration/deceleration time ratio (AT/DT): the ratio between AT and DT; (e) initial peak acceleration time (IPAT): the time elapsing from movement initiation and until the first acceleration peak.

\section{STATISTICAL ANALYSIS}

The various spatial, kinematic, and temporal parameters were analysed to divide them into groups of correlated variables. The related non-independent variables (namely, RT, AT, DT, AT/DT, MT, PV, IPAT, and IPAV) were then analysed with SAS statistical software, first by multivariate analysis of variance (MANOVA) to analyse the effect of group, visual feedback, and target location on the vector of dependent variables and then by a univariate analysis of variance (ANOVA) to analyse the effect of these factors on each variable individually. The independent variables (FEM, FED) were analysed only by ANOVA. For both analyses, a logarithmic transformation was employed to stabilise the variances.

The model included four main effects (three fixed and one random), three two way interactions and one three way interaction. ${ }^{23}$
Figure 2 Examples of pathological behaviour in patients with ITD. Hand paths, velocity, and acceleration profiles of proximally aimed movements are shown for two patients with ITD $(S 1, S 2)$ and an age matched control (C1). Upper and lower panels show respectively

movement records obtained under visual feedback and no visual feedback conditions. The control subject showed straight paths and bell shaped symmetric velocity profiles. The paths for patients with ITD were not straight. Their velocity profiles were asymmetric, showing a longer deceleration phase. This asymmetry further deteriorated in the no visual feedback conditions.

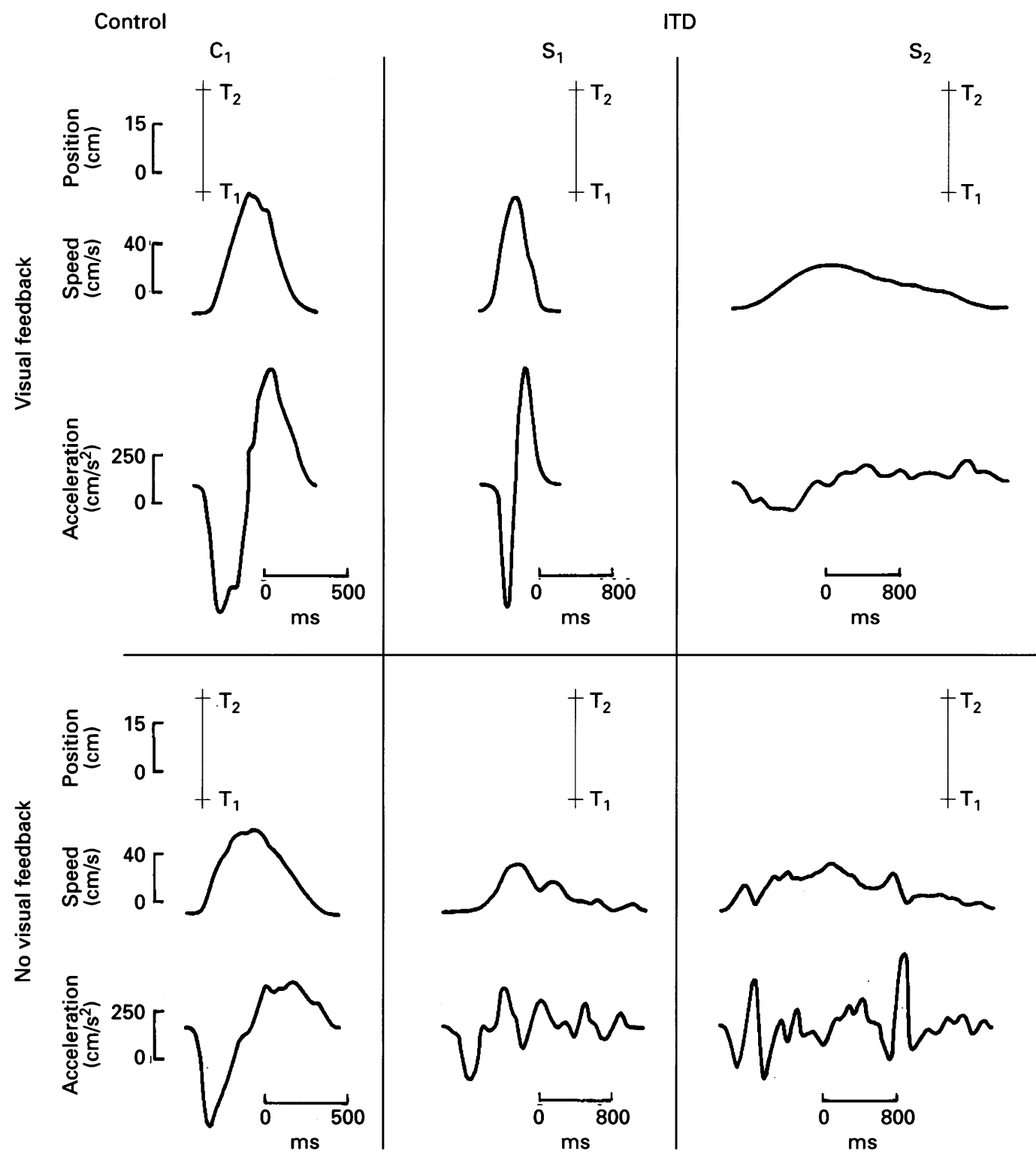


The fixed effects were group (patients/controls), visual feedback condition (vision/no vision), and target location with respect to the subject (distal/proximal). The random effect was the subject, which was nested within the group.

We used a three factor ANOVA $(2 \times 2$ $\times 2$ ) with repeated measures on the last two effects ${ }^{23}$ : for each visual feedback condition/target location combination we had six control subjects and eight patients, where each subject repeated each combination 10 times. Univariate analyses of variance for each of the two subject groups (controls and dystonia) were also performed separately.

\section{Results}

QUALITATIVE RESULTS

Figure 2 shows examples of hand paths and the corresponding acceleration and velocity profiles of individual responses recorded from one control and two patients with ITD. The movements shown in this figure are all directed toward the proximal target. The upper panel in fig 2 displays movements per- formed in the presence of visual feedback (vfb), and the lower panel displays movements performed in the no visual feedback condition (nvfb). Figure 3 shows distally directed movements recorded from the same subjects under both visual feedback conditions.

Under the vfb condition, control subjects performed straight hand paths with roughly symmetric bell shaped velocity profiles. Qualitatively, the hand paths of the movements generated by patients with ITD were often not as straight as those of neurologically healthy controls. Their velocity profiles were asymmetric and the decelerative part was longer. Under nvfb conditions - that is, when the subject could see the target but not the moving limb - the velocity profiles of patients with ITD but not of control subjects showed greater asymmetry due to further prolongation of the decelerative part compared with the $v f b$ condition (figs 2,3 ).

In patients with ITD, but not in controls, the final errors were substantially larger under nvfb conditions than under vfb conditions (fig 4).
Figure 3 Examples of trajectory records for distally aimed movements in the same subject group as in fig 2 . See fig 2 for legend description.

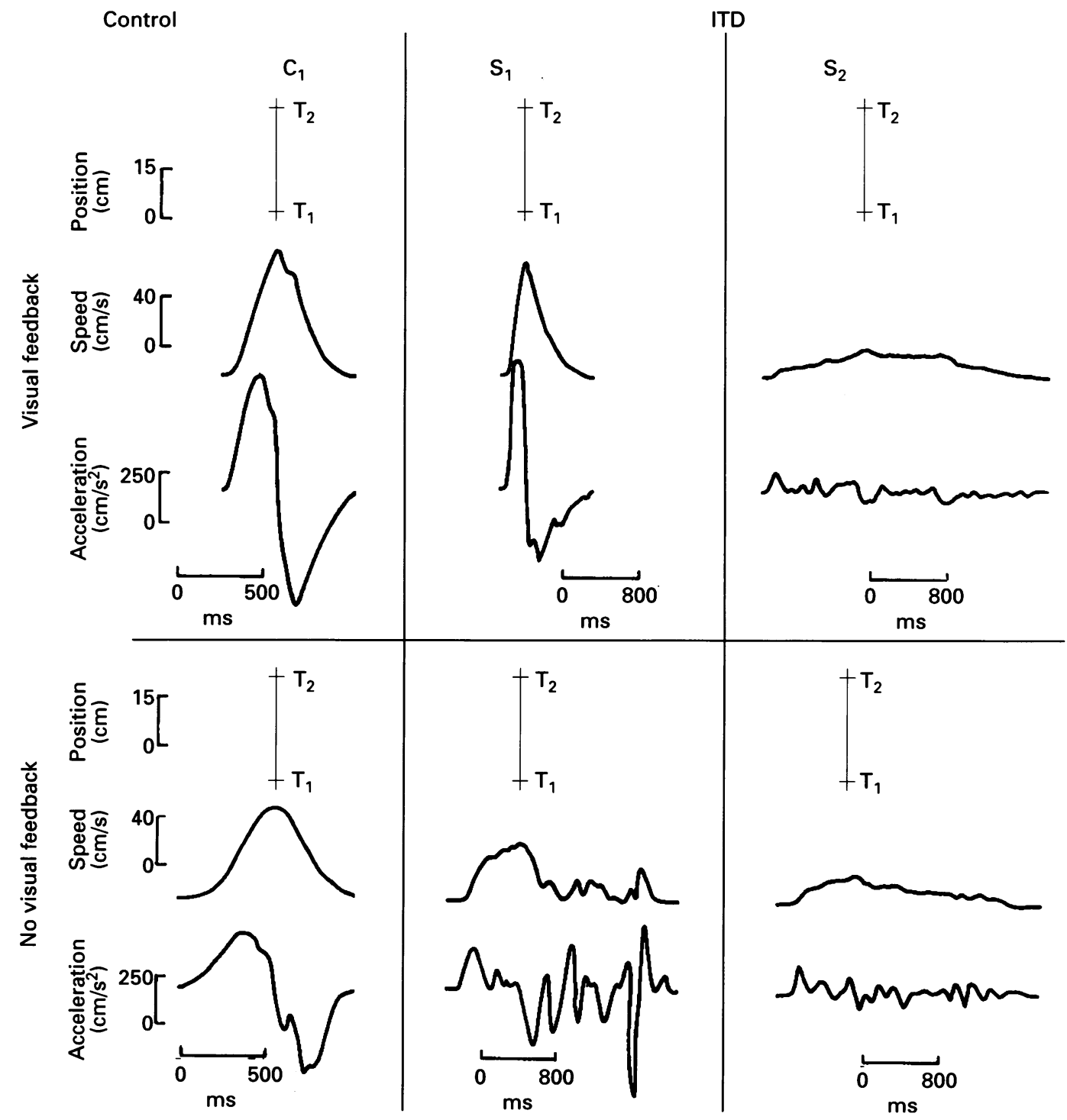


Figure 4 Final error vectors for ITD and age matched controls. Thin lines correspond to control subjects' final error vector and thick lines to those of patients with ITD. Solid lines represent the visual feedback condition and dotted lines the no visual feedback condition. The length of the arrow is proportional to the error magnitude. Note the increase in the final error magnitude under the no visual feedback condition in patients with ITD.

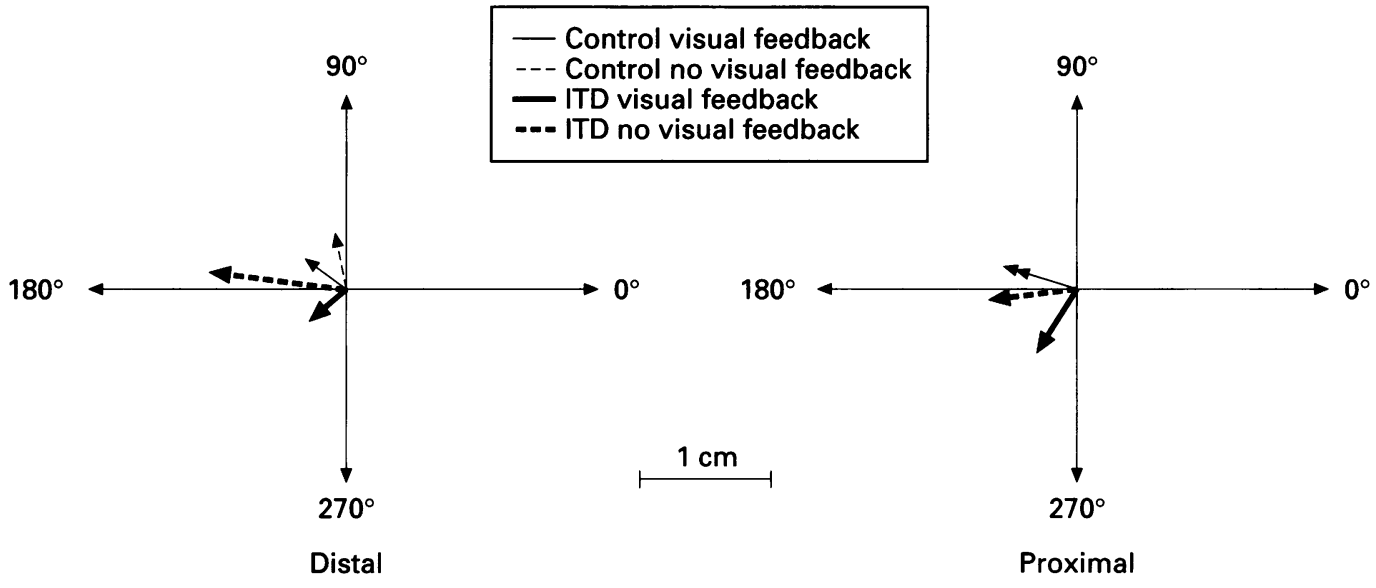

QUANTITATIVE RESULTS

Table 2 summarises the values of the temporal and spatial variables and table 3 summarises the results of the analysis of the two way ANOVA (with factors: visual feedback condition and target location) of control subjects and patients with ITD separately.

\section{Group effect}

Overall in the group $\times$ visual feedback $\times$ target location analysis, the main difference between control subjects and patients with ITD was manifested by the AT/DT ratio, which was significantly smaller in patients with ITD $(0.56$ in ITD $v 0.76$ in controls, $\mathrm{p}<$ 0.01 , table 2 ). This result reflects the greater asymmetry of the velocity profiles of patients with ITD previously mentioned in the qualitative description of the movement characteristics (see previous section and figs 2,3 ). The ATs were similar between groups (table 2), whereas the DTs were longer in patients with ITD; this difference was only marginally significant $(1021 \mathrm{~ms} v 666 \mathrm{~ms}, 0.05<\mathrm{p}<0.1)$. The total MT did not differ in a statistically significant way between groups, although it was longer in patients with ITD (1492 ms $v$ $1112 \mathrm{~ms}$, table 2). This lack of statistical sig- nificance between values which are arithmetically so different may be due to the large variability in the subjects' performances (table 2).

\section{The visual feedback effect}

In the group $\times$ visual feedback $\times$ target location analysis, the effect of visual feedback was seen on the AT/DT ratio, which was smaller during the nvfb condition than during the vfb condition $(0.60 v 0.67, \mathrm{p}=0.057)$ thus indicating that the velocity profiles became less symmetric under nvfb conditions. The final error magnitude (FEM) was larger in the nvfb conditions than in the vfb conditions $(0.71 \mathrm{~cm}$ $v 0.46 \mathrm{~cm}, \mathrm{p}=0.052$, table 2).

The separate analysis of the performances of the two groups indicated that the visual feedback effect was manifested in the AT/DT ratio only in patients with ITD and not in controls. This ratio decreased significantly during nvfb $(0.61$ during vfb $v 0.51$ during nvfb, $p<0.05)$. Whereas AT was not influenced by vfb, DT was longer in nvfb conditions (936 ms $v 1106 \mathrm{~ms}, \mathrm{p}=0.071$ ). The MT was slightly longer in nvfb conditions (1556 ms $v 1428 \mathrm{~ms}$ ) but this difference did not reach statistical significance. The final error magnitude was greater during the nvfb

Table 2 Temporal and kinematic variable values (mean (SD))

\begin{tabular}{|c|c|c|c|c|c|}
\hline \multirow[b]{2}{*}{ Variable } & \multirow[b]{2}{*}{ Group } & \multicolumn{2}{|l|}{ Distal target } & \multicolumn{2}{|l|}{ Proximal target } \\
\hline & & $v f b$ & $n v f b$ & $v f b$ & $n v f b$ \\
\hline RT (ms) & $\begin{array}{l}\text { Control } \\
\text { ITD }\end{array}$ & $\begin{array}{l}383(95) \\
384(119)\end{array}$ & $\begin{array}{l}408(125) \\
448(226)\end{array}$ & $\begin{array}{l}342(98) \\
363(122)\end{array}$ & $\begin{array}{l}347(109) \\
343(103)\end{array}$ \\
\hline $\mathrm{MT}(\mathrm{ms})$ & Control & $1156(188)$ & $1138(247)$ & $1124(170)^{\circ}$ & $1028(251)$ \\
\hline & ITD & $1395(557)$ & $1547(672)$ & $1460(624)$ & $1564(711)$ \\
\hline AT (ms) & Control & $457(116)$ & $442(135)$ & $486(105)$ & $437(103)$ \\
\hline & ITD & $437(158)$ & $462(199)$ & $546(165)$ & $489(220)$ \\
\hline DT (ms) & $\begin{array}{l}\text { Control } \\
\text { ITD }\end{array}$ & $\begin{array}{l}699(170) \\
958(445)\end{array}$ & $\begin{array}{r}693(214) \\
1137(621)\end{array}$ & $\begin{array}{l}635(159) \\
914(536)\end{array}$ & $\begin{array}{r}591(204) \\
1076(580)\end{array}$ \\
\hline AT/DT & Control & $0.71(0.35)$ & $0.70(0.29)$ & $0.82(0.28)$ & $0.80(0.30)$ \\
\hline & ITD & $0.51(0.22)$ & $0.49(0.40)$ & $0.71(0.29)$ & $0.52(0.24)$ \\
\hline PV (ms) & Control & $48(11)$ & $50(11)$ & $46(11)$ & $48(10)$ \\
\hline & ITD & $\begin{array}{c}46(19) \\
749(131)\end{array}$ & $\begin{array}{c}48(21) \\
761(154)\end{array}$ & $\begin{array}{c}45(21) \\
782(107)\end{array}$ & $\begin{array}{r}48(22) \\
739(93)\end{array}$ \\
\hline PPAT (ms) & $\begin{array}{l}\text { Control } \\
\text { ITD }\end{array}$ & $781(172)$ & $793(215)$ & 785 (135) & 755 (117) \\
\hline $\operatorname{IPAV}\left(\mathrm{m} / \mathrm{s}^{2}\right)$ & Control & $190(68)$ & $220(84)$ & $175(64)$ & $206(67)$ \\
\hline & ITD & $234(159)$ & $234(163)$ & $164(128)$ & $209(158)$ \\
\hline FEM (cm) & Control & $0.34(0 \cdot 18)$ & $0.43(0.18)$ & $0.52(0.45)$ & $0.61(0.54)$ \\
\hline & ITD & $0.36(0.26)$ & $1.02(0.89)$ & $0.60(0.51)$ & $0.72(0.43)$ \\
\hline FED (degrees) & Control & $151(93)$ & $101(67)$ & $165(95)$ & $164(124)$ \\
\hline & ITD & $214(64)$ & $177(116)$ & $236(97)$ & $185(113)$ \\
\hline
\end{tabular}

$\mathrm{RT}=$ Reaction time; $\mathrm{MT}=$ movement time; $\mathrm{AT}=$ acceleration time; $\mathrm{DT}=$ deceleration time; $\mathrm{PV}=$ peak velocity, IPAT $=$ initial peak acceleration value; IPAV = initial peak acceleration time; FEM = final error magnitude; FED = final error direction; vfb = veak acceleration value; 1 feedback condition; nvfb = no visual feedback condition. 
Table 3 Temporal, spatial, and kinematic variables: data derived from ANOVA performed separately in controls and patients with ITD

\begin{tabular}{|c|c|c|c|c|c|c|}
\hline \multirow[b]{2}{*}{ Variable } & \multirow{2}{*}{\multicolumn{2}{|c|}{ Visual feedback condition }} & \multicolumn{4}{|l|}{ Factors } \\
\hline & & & \multicolumn{2}{|c|}{ Target location } & \multicolumn{2}{|c|}{$\begin{array}{l}\text { Visual feedback } \\
\text { target location }\end{array}$} \\
\hline & Control & ITD & Control & ITD & Control & ITD \\
\hline RT & - & - & + & + & - & + \\
\hline MT & - & - & - & - & - & - \\
\hline AT & - & - & - & ++ & - & ++ \\
\hline DT & - & \pm & - & - & - & - \\
\hline AT/DT & - & + & - & + & - & - \\
\hline PV & - & - & - & - & - & - \\
\hline IPAT & - & - & - & - & - & - \\
\hline IPAV & - & - & - & \pm & - & ++ \\
\hline FEM & - & + & - & - & - & - \\
\hline FED & - & - & - & - & - & - \\
\hline
\end{tabular}

$++=\mathrm{p}<0.01 ;+=\mathrm{p}<0.05 ; \pm=0.05<\mathrm{p}<0.1 ;-=$ non-significant.

For abbreviations see table 2 . conditions than in the vfb conditions $(0.87$ $\mathrm{cm} v 0.48 \mathrm{~cm}, \mathrm{p}<0.05$; table 2 , fig 4$)$.

\section{Target location effect}

Overall in the group $\times$ visual feedback $\times$ target location model, a significant effect of target location was seen on RTs. Distally aimed movement RTs were longer than those of proximally aimed ones $(409 \mathrm{~ms} v 350 \mathrm{~ms}$, $\mathrm{p}<0.01)$. This effect was also seen in both groups when separately analysed.

The AT/DT ratio was significantly larger for proximally aimed movements $(0.69 v$ $0.59, \mathrm{p}<0.01$ ); ATs of proximally aimed movements were significantly longer than distally aimed ATs $(p<0.01)$ whereas DTs were not influenced by target location. A significant interaction was found between group and target location $(p<0.05)$. Whereas ATs of proximally aimed movements were also longer in controls, this prolongation was more prominent in patients with ITD. The PVs were higher for distally aimed movements $(48 \mathrm{~m} / \mathrm{s} v$ $46 \mathrm{~m} / \mathrm{s}, \mathrm{p}<0.05$ ) as well as the IPAVs which were higher for distally aimed movements $\left(223 \mathrm{~m} / \mathrm{s}^{2} v 189 \mathrm{~m} / \mathrm{s}^{2}, \mathrm{p}=0.055\right.$, tables 2,3$)$. The RTs of distally aimed movements were significantly longer than those of proximally aimed movements both in controls and in patients with ITD. Final errors were not affected by target location (tables 2,3 ).

When groups were analysed separately for the effect of target location, statistically significant effects on AT/DT, AT, and IPAV were found only in patients with ITD and not in controls. The ATs and AT/DT ratios of proximally aimed movements were larger, and IPAVs were greater in distally aimed movements (tables 2,3 ).

\section{Discussion}

In the present study we have presented a kinematic analysis of upper limb trajectories in patients with ITD and age matched neurologically healthy controls. This analysis has mainly focused on the effects of visual feedback from the limb and of movement directions on the temporal, spatial, and kinematic parameters characterising the movements.

Our findings showed normal reaction times in patients with ITD, indicating that move- ment preparation is normal in this disease. On the other hand, although their movement times were not significantly longer than normal as a group, in some patients with ITD movement execution was much slower than in control subjects. This variability and slowness of movement execution in ITD is in agreement with findings in a previous study concerned with elbow movements in ITD ${ }^{13}$ In this respect, our results are also reminiscent of the well known bradykinesia of Parkinson's disease $^{24}$ and Huntington's disease. ${ }^{25}$ Slowness of movement seems therefore to represent a more generalised feature of basal ganglia diseases, despite different symptoms of either hypokinesia or hyperkinesia such as chorea or dystonia.

Focusing closer on the velocity profiles we attempted a more detailed analysis of the trajectories by further examining the accelerative and decelerative phases of the movement. The generation of roughly symmetric bell shaped velocity profiles in healthy subjects reflects the fact that the durations of both components are almost equal, although the decelerative phase might be longer under more stringent accuracy demands. ${ }^{17}$ In fact, the mean AT/DT ratio in our normal control subjects was 0.76 , and 0.56 in ITD. The major abnormality in the trajectories of the patients was the long decelerative component, which became even longer when visual feedback from the limb was withdrawn. These findings could suggest a specific defect in the second part of the movement-that is, in the integration of "corrective" information into the motor plan. The validity of this interpretation can be investigated in several ways. One approach might involve the comparison of the kinematic properties of fast and slow movements. The rationale of such an approach is that the dependency on feedback information is of relatively less significance during fast movements, as such movements operate mostly under "open loop" conditions, by contrast with slower movements, which are subject to a mode involving continuous feedback based corrections. Indeed, Van Der Kamp et $a l,{ }^{13}$ who have analysed the kinematic properties of rapid elbow movements in ITD, have noted equal durations of the acceleration and deceleration phases in such movements and have concluded that motor programmes involved in the execution of rapid movements are relatively preserved in ITD. This symmetry of the velocity profile in relatively fast movements compared with the asymmetry we found in relatively slow movements, might therefore indicate deficits in the integration of feedback corrections in patients with ITD or the use of a strategy based on verifying their performance (see later). In the present study, we used another approach by analysing motor performance under conditions in which the movement is more dependent on kinaesthetic information-that is, in darkness.

Among the various sensory modes influencing the preparation and execution of movements, visual, proprioceptive, and possibly efferent copy information ${ }^{26}$ play important 
parts. Visual information is necessary for the localisation of the target and for the comparison of hand and target positions during the movement, particularly in the final adjustment stage. When vision of the moving limb is not available, the magnitude and direction of the required movement amplitude is determined by comparing the target position derived from vision with kinaesthetic information enabling the assessment of the limb's position. In primates and healthy humans, inability to see the moving limb does not significantly affect the temporal features of reaching movements ${ }^{27}$ as was also noted in the present study. On the other hand, we noted that in the absence of visual feedback, the velocity profiles of patients with ITD showed increased asymmetry due to a longer decelerative phase and a deterioration of the final accuracy.

Possibly the slowing in the deceleration phase is due to the inability of patients with ITD to rely on afferent information. When vision of the limb is available, they can verify their progress by comparing their hand position against the target location and obtain accuracy levels similar to controls. When vision of the limb is withdrawn, they move more slowly to compensate for the lesser amount of information. The fact that the final accuracy deteriorates without visual feedback only in patients with ITD and not in control subjects, despite the relative decrease in movement speed, might also suggest a deficit in the integration of proprioceptive or efferent copy information into the descending motor command.

A new finding that emerged from this study relates to the similarities between the movement characteristics in ITD and Parkinson's disease. For example the abnormal dependency on visual cues from the moving limb, as was shown here in patients with ITD, was previously reported in monkeys with lesions in the substantia nigra and in patients with Parkinson's disease. A significant increase in final errors occurred in the absence of visual feedback from the limb. ${ }^{19}{ }^{20}$ The deterioration of performance in ITD, however, seems to occur mostly in the decelerative part of the movement and in the final error, whereas in Parkinson's disease, both the accelerative and decelerative phases are affected by the absence of visual feedback. ${ }^{19}$ Thus it seems that in ITD, the integration of sensory information into the motor plan is disturbed, whereas in Parkinson's disease, in addition to similar abnormal processes, the planning of the initial acceleration is also deficient.

Other similarities between ITD and Parkinson's disease relate to spatial effects. A new finding consists of the differences that exist in RT as a function of movement direction. Van Sonderen $e t a^{88}$ found longer RTs in healthy young controls when movements were directed away from the body, than in those directed toward the body. Our findings in both normal controls and in patients with ITD were similar. We have previously shown prolongations of RTs for distally aimed move- ments in elderly healthy subjects and pronounced prolongations in patients with Parkinson's disease. ${ }^{19}$ In patients with ITD, however, the magnitude of the effect of target location on RT was similar to that seen in controls.

The effect of direction of movement was also reflected in the values of movement acceleration in patients with ITD. Initial peak accelerations were higher and acceleration times were shorter for distally aimed movements compared with movements aimed towards the body in patients with ITD but not in controls. Similar results were found by us in patients with Parkinson's disease ${ }^{19}$ and by Camarata $e t a l^{9}$ in monkeys treated with 1methyl-4-phenyl-1,2,5,6 tetrahydropyridine. It is possible that in ITD and in Parkinson's disease, deficits in the evaluation of limb configuration and subsequent abnormalities in the ability to generate appropriate muscle forces in accordance with the variations in limb inertia as a function of arm configuration, result in the inadequacies in initial accelerations reflected by these findings. Similar abnormalities were reported in deafferented patients. $^{30}$

Another analogy between patients with ITD and deafferented patients is the deterioration of motor performance in patients with ITD in the absence of visual feedback, expressed by the increase in final errors and the prolongation of deceleration time under these conditions. For example, Teasdale $e t a^{31}$ studied drawing movements by a deafferented limb and noted that in the absence of visual feedback the shape of drawn figures remains consistent, whereas their spatial location drifts. Still, the deficits occurring in ITD, although reminiscent of findings in deafferented patients, are of smaller magnitude. Conscious proprioception is probably normal in ITD, as are the anatomy and innervation of muscle spindles. ${ }^{32} \mathrm{~A}$ central deficit in subconscious assessment of proprioceptive information, however, seems to exist, requiring extra reliance on visual feedback, as shown in this study.

Thus ITD might not necessarily be a pure motor disorder but may involve complex deficits in sensorimotor integration. The reported similarities between the kinematic abnormalities of limb movements of patients with ITD or Parkinson's disease, and the effects of visual feedback and movement direction on motor performance, may indicate that similar functional pathways enrolled in such functions are affected in Parkinson's disease and ITD.

This work was supported in part by the Yeda Fund of the Weizmann Institute of Science, by grants Nos 85-00395 and 88-00141 from the United States-Israel Binational Science Foundation (BSF), Jerusalem, Israel, and by the Israel Ministry of Health, Chief Scientist.

1 Zilber N, Korczyn AD, Kahana E, Fried K, Alter M. Inheritance of idiopathic torsion dystonia among Jews. IMed Genet 1984;21:13-20.

2 Gasser T, Fahn S, Breakfield Xo. The autosomal dominant dystonias. Brain Pathology 1992;2:297-308.

3 Korczyn AD, Inzelberg R. Dystonia. Curr Opin Neurol Neurosurg 1993;6:350-7.

4 Marsden CD, Obeso JA, Zarranz JJ, Lang AE. The 
anatomical basis of symptomatic hemidystonia. Brain 1985;108:463-83.

5 Cohen LG, Hallett M. Hand cramps: Clinical features and electromyoraphic patterns in a focal dystonia. Neurology 1988;38:1005-12.

6 Hughes M, McLellan DL. Increased co-activation of upper limb muscles in writer's cramp. $₹$ Neurol Neurosurg Psychiatry 1985;48:782-7.

7 Sheehy MD, Marsden CD. Writer's cramp, a focal dystonia Brain 1982:105:461-80.

8 Yanagisawa N, Goto A. Dystonia musculorum deformans. Analysis by electromyography. $\mathcal{F}$ Neurol $S c i$ 1971;13: 39-65.

9 Ghez C, Gordon S, Hening W. Trajectory control in dystonia. Adv Neurol 1988;50:141-55

10 Nakashima K, Rothwell JC, Day BL, Thompson PD, Shannon K, Marsden CD. Reciprocal inhibition between forearm muscles in patients with writer's cramp and other occupational cramps, symptomatic hemidystonia and hemiparesis due to stroke. Brain 1989;112: 681-97.

11 Rothwell JC, Day BL, Obeso JA, Berardelli A, Marsden $\mathrm{CD}$. Reciprocal inhibition between muscles of the hum

12 Panizza ME, Lelli $S$, Nilsson J, Hallett $M$. H-reflex recovery curve and reciprocal inhibition of H-reflex in different kinds of dystonia. Neurology 1990;40:824-48.

13 Van Der Kamp W, Berardelli A, Rothwell JC, Thompson PD, Day BL, Marsden CD. Rapid elbow movements in patients with torsion dystonia. F Neurol Neurosurg Psychiatry 1989;52:1043-9.

14 Sanes JN, Evarts EV. Psychomotor performance in Parkinson's disease. In: Delwaide PJ, Agnoli A, eds. Clinical Neurophysiology in Parkinsonism. BV North Holland: Elsevier 1985:117-32.

15 Hollerbach JM, Flash T. Dynamic interactions between limb segments during planar arm movements. Biol Cybern 1982;44:67-77.

16 Flash T, Hogan N. The coordination of arm movement: an experimentally confirmed mathematical model. an experimentally confirm

17 Georgopoulos AP. On reaching. Ann Rev Neurosci 1986; 9:147-70.

18 Woodworth RS. The accuracy of voluntary movement Physiological Monograph Suppl New York: Macmillan, 1899;13:1-114.

19 Flash $\mathrm{T}$, Inzelberg $\mathrm{R}$, Korczyn $\mathrm{AD}$. Kinematic properties of upper limb trajectories in Parkinson's disease. Exp Neurol 1992;118:215-26.
20 Viallet F, Trouche E, Beaubaton D, Legallet E. The role of visual reafferents during a pointing movement: comparative study between open-loop and closed-loop performances in monkeys before and after unilateral electrolytic lesion of substantia nigra. Exp Brain Res 1987;65:399-410.

21 Inzelberg $\mathrm{R}$, Kahana $\mathrm{E}$, Korczyn $\mathrm{AD}$. Clinical course of idiopathic torsion dystonia among Jews in Israel. $A d v$ Neurol 1988;50:93-100.

22 Korczyn AD. Genetics of idiopathic torsion dystonia in Ashkenazi Jews. In: Bonne-Tamir B, Adam A, eds. Genetic diversity among fews. Oxford: Oxford University Press, 1992:194-201

23 Winer. Statistical principles in experimental design. McGrawHill, 1971 .

24 Marsden CD. The mysterious motor function of the basa ganglia: the Robert Wartenberg lecture. Neurology 1982; 32:514-39.

25 Thompson PD, Berardelli A, Rothwell JC, Day BL, Dick IPR, Benecke $R$, Marsden $C D$. The coexistence of bradykinesia and chorea in Huntington's disease and its implications for theories of basal ganglia control of movement. Brain 1988;111:223-44.

$26 \mathrm{McCloseky}$ DL. Corollary discharge: motor commands and perception. In: Brooks VB, ed. Handbook of physiol and perception. In: Brooks $\mathrm{VB}$, ed. Handbook of physiolBethesda: American Physiological Association, 1981. Bethesda:

27 Carlton LG. Visual information: The control of aiming movements. Qf Exp Psychol 1981;33A:87-93.

28 Van Sonderen JF, Van Gielen CCAM, Denier van De Gon JJ. Motor programmes for goal-directed movements are continuously adjusted according to target location. Exp Brain Res 1989;78:139-46.

29 Camarata PJ, Parker RG, Park SK, Haines SJ, Turner DA Chae $\mathrm{H}$ et al. Effects of 1-methyl-4-phenyl-1,2,5,6 tetrahydropyridine (MPTP) induced hemi-parkinsonism on the kinematics of a two-dimensional multi-joint arm movement in the rhesus monkey. Neuroscience 1992; 48:607-19.

30 Ghez C, Gordon S, Ghilardi MF, Christakos CN, Cooper $\mathrm{SE}$. Roles of proprioceptive input in the programming of arm trajectories. Cold Spring Harb Symp Quant Biol arm trajectories.

31 Teasdale N, Forget R, Bard C, Paillard J, Fleury M, Lamarre $Y$. The role of proprioceptive information for the production of isometric forces and for hand-writing tasks. Acta Psychol (Amst) 1993;82:179-91.

32 Swash M, Fox KP. Normal muscle spindles in idiopathic torsion dystonia. $\mathcal{F}$ Neurol Sci 1976;27:525-7.

\section{Thomas Sydenham and Richard Bright on} chorea

Thomas Sydenham, known as "The British Hippocrates" wrote little of neurological diseases, but his description of chorea ${ }^{1}$ is a classic.

"There is a kind of convulsion, which attacks boys and girls from the tenth year to the time of puberty. It first shows itself by limping or unsteadiness in one of the legs, which the patient drags. The hand cannot be steady for a moment. It passes from one position to another by a convulsive movement, however much the patient may strive to the contrary. Before he can raise a cup to his lips, he does make as many gesticulations as a mountebank; since he does not move it in a straight line, but has his hand drawn aside by the spasms, until by some good fortune he brings it at last to his mouth. He then gulps it off at once, so suddenly and so greedily as to look as if he were trying to amuse the lookers-on."

Chorea (Greek: dance), was used to describe the dancing manias. During an outbreak in 1418 sufferers were regarded as hysterics. They were enjoined to repair to the chapels of St Vitus at Zabern near Strasbourg to plead for the Saint's intervention. A Sicilian martyr under Diocletian (AD 303), St Vitus's remains were moved to France, and, because he was patron of dancers and actors, his altar was used to seek relief from the dancing plague. The dancing mania was a source of great terror: Burton's Anatomy of melancholy (1621) refers to "Chorus Sancti Viti ... they that are taken with it can do nothing but dance till they be dead, or cured."

Sydenham's account made no mention here, nor in chapter 10 "On Rheumatism" that he recognised the association with rheumatic fever. Indeed this association was forged in 1831 by Richard Bright (1797-1858)2:

"A general irritation which so strongly marks chorea" The acute form primarily affected children, in which "we have seen that rheumatism is so intimately connected ... a a peculiar connection." The work of Germaine Sée in 1850 distinguished Sydenham's chorea from paralysis agitans, though mis-citing Parkinson as "Patterson."

J M S PEARCE

1 Sydenham T. On St Vitus's dance. The works of Thomas Sydenham, $M D$. Translated from the Latin edition of Dr Greenhill with a life of the author by RG Latham MD Vol 2. London: The Sydenhain Society, 1850: 257-9.

2 Bright R. Reports of medical cases. Vol 2 Disease of the brain and nervous system: selected with a view of illustrating the symptoms and cure of diseases by reference to morbid anatomy London: Longman, 1831:493.

3 Brown J. Locke and Sydenham and other papers. Edinburgh: David Douglas, 1882:33-135. 